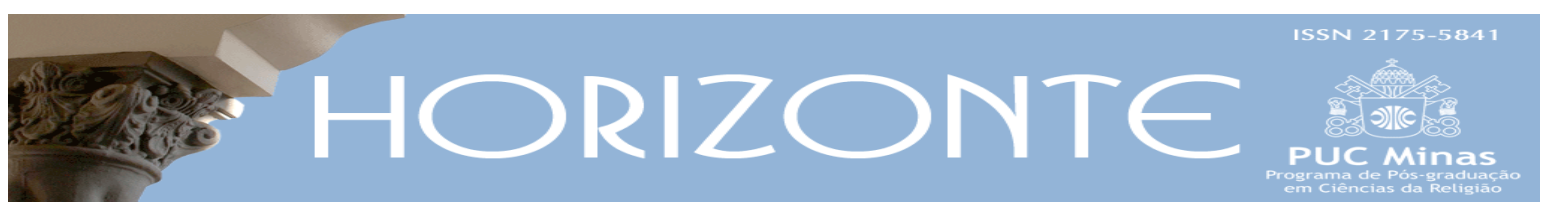

Dossiê: Conferência de Puebla: 40 anos - Artigo original (a) (1)

\title{
A opção preferencial pelos pobres diante da aporofobia: reflexões antropológicas para uma atualização da opção de Puebla
}

\author{
The preferential option for the poor in the face of the Aporophobia: \\ Anthropological Reflections for an update of Puebla option
}

Lúcia Pedrosa-Pádua*

\begin{abstract}
Resumo
O artigo atualiza um tema fundamental da Conferência de Puebla (1979), a opção preferencial pelos pobres, através do diálogo com o tema da aversão pelos pobres, ou aporofobia, estudado pela filósofa Adela Cortina. Apresenta os significados da opção preferencial pelos pobres, inaugurada em Medellín e solenemente proclamada em Puebla e mostra como esta opção foi assumida pelo magistério posterior, tanto na América Latina quanto no magistério universal; em seguida, sistematiza os aspectos da aporofobia ressaltados por Adela Cortina e, ao final, propõe cinco desafios teológico-pastorais: redescobrir a opção pelos pobres como graça, perceber a necessidade do envolvimento emocional com os pobres, descobrir a riqueza dos pobres e recusar o discurso do ódio, refletir sobre caminhos para eliminar a pobreza e contribuir para uma nova economia. Em tudo isto, o magistério de Francisco mostra-se profundamente iluminador. Podemos dizer que, com o Papa Francisco, é aprofundado um caminho profético de inclusão, convivência e responsabilidade globais, que visibiliza e inclui os pobres e, assim, enfrenta a aporofobia.
\end{abstract}

Palavras-chave: Opção preferencial pelos pobres. Aporofobia. Puebla. Papa Francisco.

\begin{abstract}
This article updates a fundamental theme of the Conference of Puebla (1979), the preferential option for the poor, through dialogue with the theme of aversion by the poor, of the philosopher Adela Cortina. Presents the meanings of the preferential option for the poor inaugurated in Medellín and solemnly proclaimed in Puebla and shows how this option was assumed by the posterior documents, both in Latin America and in the universal magisterium; then systematizes some aspects of the Aporophobia and, at the end, proposes five theological-pastoral challenges: rediscover the option for the poor as Grace, realize the need for emotional involvement with the poor, discover the wealth of the poor and refuse the hate speech, reflect on ways to eliminate poverty and contribute to a new economy. In all this, the Magisterium of Francis is deeply illuminator. We can say that, with Pope Francis, a prophetic path of inclusion, coexistence and global responsibility is deepened, which turns visible and includes the poor and thus faces aporophobia.
\end{abstract}

Keywords: Preferential option for the poor. Aporophobia. Puebla. Pope Francis.

Artigo submetido em 31 de agosto de 2019 e aprovado em 23 de dezembro de 2019.

* Doutora em Teologia pela PUC-Rio. Professora da PUC-Rio. País de origem: Brasil. E-mail: Ipedrosa@puc-rio.br 


\section{Introdução}

Lembro-me que, enquanto estudante de Teologia na FAJE, deixava-me impressionar com a descrição que o saudoso Pe. Libanio, SJ, fazia da relação entre as Conferências Episcopais de Medellín e Puebla. Com sua peculiar entonação acompanhada de gestos, explicava: "Medellín abriu o caminho e Puebla o pavimentou". Vinham-me à mente o trabalho de capina e a delineação da estrada da primeira conferência e, da segunda, a organização das palavras. Fazia parte desta "pavimentação" a proclamação da "opção preferencial pelos pobres", que tanto impactou e influenciou a Igreja posteriormente.

No contexto atual, vemos esta opção desafiada pela aporofobia, ou aversão aos pobres, recentemente estudada por Adela Cortina. Este artigo investiga esta contraposição e aponta para os caminhos de superação que vêm sendo dados, na direção de uma atualização, sempre necessária, da opção preferencial pelos pobres.

\section{A opção pelos pobres em Puebla}

Voltar aos textos de Puebla é imprescindível, para que se tornem vivas as palavras e a intencionalidade que permearam a opção preferencial pelos pobres.

A esteira luminosa foi aberta pela II Conferência do Episcopado Latinoamericano. Medellín (1968) impactou. Denunciou o escândalo da pobreza no continente: "Um surdo clamor nasce de milhões de homens, pedindo a seus pastores uma libertação que não lhes chega de nenhuma parte" (MEDELLÍN, 2005, p. 200, n. 14.2). A denúncia é acompanhada da conclamação à libertação integral do ser humano, que se dá na conexão com o trabalho nas estruturas injustas geradoras de injustiça e com o testemunho pessoal e comunitário de uma “Igreja-sinal” (MEDELLÍN, 2005, p. 143, n. 7.13, 5).

Em continuidade com as intuições mais profundas de Medellín, a II Conferência, em Puebla (1979), proclamou a "opção preferencial pelos pobres", que teria profundas consequências para a vivência do cristianismo na América Latina e 
no mundo. Eis o texto: “A Conferência de Puebla volta a assumir, com renovada esperança na força vivificadora do Espírito, a posição da II Conferência Geral que fez clara e profética opção preferencial e solidária pelos pobres" (PUEBLA, 2005, p. 547, n. 1134). Logo em seguida, conclama a Igreja à conversão: “Afirmamos a necessidade de conversão de toda a Igreja para a opção preferencial pelos pobres, no intuito de sua integral libertação" (PUEBLA, 2005, p. 547, n. 1134).

Esta opção é "exigida pela escandalosa realidade dos desequilíbrios econômicos da América Latina", afirma Puebla e tem a missão de "levar a estabelecer uma convivência humana digna e a construir uma sociedade justa e livre" (PUEBLA, 2005, p. 551, n. 1154).

Falar sobre os pobres e a pobreza não é perder-se nas abstrações, o que seria improdutivo para a práxis cristã. Puebla inaugura a descrição das "feições concretíssimas” que a extrema pobreza generalizada adquire no continente, nas quais “deveríamos reconhecer as feições sofredoras de Cristo, o Senhor (que nos questiona e interpela)" (PUEBLA, 2005, p. 300, n. 31s): as crianças golpeadas pela pobreza ainda antes de nascer, impedidas de um desenvolvimento saudável; crianças abandonadas e exploradas nas cidades; jovens que não encontram o seu lugar na sociedade, tanto nas zonas rurais quanto urbanas; indígenas e afroamericanos, "os mais pobres dentre os pobres"; camponeses e sem-terra segregados; operários mal remunerados e sem direitos; subempregados e desempregados submetidos aos frios modelos de desenvolvimento; marginalizados e amontoados das cidades; anciãos cada dia mais numerosos e marginalizados.

A fundamentação da opção pelos pobres é cristológica: a causa dos pobres é a causa de Cristo. Por isso, na Mensagem aos povos da América Latina, os bispos convidam a todos, sem distinção de classes, a aceitar e assumir a causa dos pobres, “como se estivessem assumindo e aceitando sua própria causa, a própria causa de Jesus Cristo" (PUEBLA, 2005, p. 286, n.3). 
A opção pelos pobres está inserida na evangelização entendida de maneira integral. Puebla afirma que ela constitui o "melhor serviço" ao irmão: "o serviço dos pobres é medida privilegiada, embora não exclusiva, de nosso seguimento de Cristo. O melhor serviço do irmão é a evangelização que o dispõe a realizar-se como filho de Deus, o liberta das injustiças e o promove integralmente" (PUEBLA, 2005, p, 549, n. 1145).

Importante é revisitar, hoje, as ações concretas postas pelos Bispos latinoamericanos em Puebla: condenar a pobreza extrema como antievangélica; conhecer e denunciar os mecanismos geradores de pobreza; unir esforços com outras Igrejas no combate à pobreza e criação de um mundo mais justo e fraterno; apoiar aspirações dos operários e camponeses, como homens livres e sujeitos de decisão sobre sua vida e futuro; defender o direito de organizações camponesas e operárias que defendem e promovem o bem; comprometer-se com as culturas indígenas e promove-las, com respeito e simpatia a seus valores e riquezas; manter vivo este chamado e abrir novos horizontes à esperança (PUEBLA, 2005, p. 552-553, n. 1159-1175).

A dificuldade da realização histórica desta solidariedade deve ser buscada na força de ruptura interna, que representa o pecado humano, que impede a comunhão entre os homens, que parte do coração dos homens e das estruturas por eles criadas, as estruturas de pecado "nas quais o pecado de seus autores imprimiu sua marca destruidora" (PUEBLA, 2005, p. 357, n. 281). Esta ruptura intervém no plano das relações interpessoais, imprime atitudes de egoísmo, ambição e inveja que geram injustiça, dominação e violência e todos os tipos; "corresponde à luta entre indivíduos, grupos, classes sociais e povos bem como à corrupção, ao hedonismo, à exacerbação sexual e à superficialidade nas relações mútuas" (PUEBLA, 2005, p. 373, n. 328), com sérias consequências para o exercício da liberdade de todos. 
Por isso, a opção pelos pobres deve provocar uma mudança de mentalidade e de atitudes, libertando-se a pessoa dos falsos ideais da sociedade de consumo e do coração apegado às riquezas e escravo do egoísmo (PUEBLA, 2005, p. 551, n. 1555).

A opção pelos pobres esteve presente em todas as Conferências do Episcopado latino-americano posteriores a Puebla, com especificidades.

\section{A expressão de Puebla se irradia para a América Latina e documentos universais}

A partir de Puebla, vemos uma irradiação do tema da opção preferencial pelos pobres em todas as Conferências episcopais posteriores, vários documentos universais e o fortalecimento teológico latino-americano.

A formulação tornou-se elemento basilar da teologia latino-americana da libertação e esta deve continuar oferecendo o critério profundamente evangélico da opção preferencial pelos pobres. Não está superado e nunca poderá sê-lo, por isso a intencionalidade profunda dessa teologia pode sempre atualizar o seu campo de aplicação. Baseia-se na gratuidade do amor de Deus, que ama os pobres não porque eles sejam melhores, mas porque Deus é gratuito (GUTIERREZ, 1996, p. 111). A opção pelos pobres não é uma atividade, uma opção entre outras, mas "uma atitude permanente, ética e espiritual" (CTA, 2007, p. 52).

A IV Conferência, em Santo Domingo (1992) reafirma, em suas conclusões, a mesma linha de Puebla, especialmente na parte dedicada à promoção humana (SANTO DOMINGO, 2005, p. 705-736, n. 157-227). Com relação à formulação, é mais ambígua, por um lado reforça que a "opção evangélica e preferencial pelos pobres" é "firme e irrevogável”; por outro, faz questão de acrescentar que "não é exclusiva nem excludente" (SANTO DOMINGO, 2005, p. 715, n. 178). É interessante que, em Santo Domingo, a lista dos rostos sofredores dos pobres, em que se descobre o rosto do Senhor, é ampliado e aparecem pela primeira vez o rosto das mulheres humilhadas e desprezadas e o dos migrantes. (SANTO DOMINGO, 2005, p. 716, n. 178). 
Quinze anos depois, a V Conferência, em Aparecida (2007), recolhe um importante trecho do Discurso Inaugural do Papa Bento XVI, que associa a opção pelos pobres com a fé em Jesus Cristo: “a opção preferencial pelos pobres está implícita na fé cristológica naquele Deus que se fez pobre por nós, para nos enriquecer com sua pobreza" (APARECIDA, 2007, p. 177, n. 392). O documento de Aparecida continua no mesmo parágrafo: "esta opção nasce de nossa fé em Jesus Cristo" (APARECIDA, 2007, p. 177, n. 392).

Também Aparecida amplia o rosto dos pobres, "rostos sofredores que doem em nós" (APARECIDA, 2007, p. 184, 8.6. Título). São mencionados os moradores da rua; os migrantes, deslocados e refugiados; os enfermos, com prioridade aos portadores do HIV; os dependentes de drogas e os detidos em prisões. (APARECIDA, 2007, p. 184-191, n. 407-430).

Uma novidade aparece em Aparecida. Ao mesmo tempo em que se pede que sejam evitadas atitudes paternalistas e que se promovam mudanças sociais concretas (APARECIDA, 2005, p. 179, n. 396-397), há um apelo também afetivo e emocional, o de compartilhar a vida com os pobres:

Solicita-se dedicarmos tempo aos pobres, prestar a eles amável atenção, escutá-los com interesse, acompanha-los nos momentos difíceis, escolhêlos para compartilhar horas, semana ou anos de nossa vida, e procurando, a partir deles, a transformação de sua situação. Não podemos esquecer que o próprio Jesus propôs isso com seu modo de agir e com suas palavras: "Quando deres um banquete, convida os pobres, os inválidos, os coxos e os cegos" (Lc 14,13). (APARECIDA, 2007, p. 179, n. 397).

A opção preferencial pelos pobres ecoou em importantes documentos do Magistério universal. Entra no Magistério de João Paulo II várias vezes. Em sua Encíclica social Sollicitudo Rei Socialis. Sobre a solicitude social da Igreja, 1987, afirmou que é "a opção ou amor preferencial pelos pobres [...] uma forma especial de primado na prática da caridade cristã” (1987, n. 42). A Redemptoris Missio (1990) refere-se explicitamente a Puebla e à atenção preferencial pelos pobres (1990, n. 60), a Encíclica social Centesimus Annus (1991) afirma que a opção preferencial pelos pobres acredita a mensagem social da Igreja, pois nela 
transparece "o testemunho das obras" (1991, n. 57); e na Carta Tertio Millennio Adveniente (1994), João Paulo II afirma explicitamente:

[...] recordando que Jesus veio 'evangelizar os pobres' $(M t 11,5 ; L c 7,22)$, como não sublinhar com maior decisão a opção preferencial da Igreja pelos pobres e os marginalizados? Antes, deve-se afirmar que o empenho pela justiça e pela paz num mundo como o nosso, marcado por tantos conflitos e por intoleráveis desigualdades sociais e económicas. (JOÃO PAULO II, 1994, n. 51).

De Bento XVI tornou-se famoso o seu Discurso de abertura da Conferência de Aparecida, já recolhido acima, em que afirma que "a opção preferencial pelos pobres está implícita na fé cristológica naquele Deus que se fez pobre por nós, para nos enriquecer com sua pobreza”. (APARECIDA, 2007, p. 177, n. 392).

A opção preferencial pelos pobres entrará com força, com características próprias, no Magistério do Papa Francisco, como veremos mais adiante.

Passemos agora ao movimento contrário, antropologicamente forte e politicamente dominante em países com orientações totalitárias e antidemocráticas, a aporofobia.

\section{Aporofobia ou rechaço aos pobres: o pensamento de Adela Cortina}

Autora de uma vasta obra filosófica, é em seu livro Aporofobia, el rechazo al pobre (2017) que a filósofa espanhola Adela Cortina apresenta um pensamento original e iluminador para a compreensão de alguns aspectos da enorme resistência encontrada em relação aos pobres na atual sociedade e economia globalizadas. Há hoje uma concentração de renda sem precedentes aliada a muitas formas de aversão aos pobres, migrantes e movimentos sociais, com descarte programático dos que não se adaptam à forma de desenvolvimento proposta. A aversão aos pobres acompanha a preferência de muitos cidadãos por governos liberais com tendências totalitárias. 
Vejamos em que consiste a aporofobia a partir de alguns elementos que podem ajudar na reflexão antropológica atual sobre a opção preferencial pelos pobres.

\subsection{Uma palavra nova e necessária}

Aporofobia significa fobia aos pobres. O termo foi cunhado pela própria Adela Cortina (2017), a partir da união do termo grego áporos, que significa o pobre, aquele que não possui recursos, e fobia, que designa rechaço, aversão, desprezo, hostilidade, temor ou mesmo ódio (CORTINA, 2017, p. 22-27). Assim sendo, a aporofobia pode ser traduzida como rechaço ou aversão aos pobres. Para Adela Cortina, o termo é necessário para visibilizar uma realidade ainda inominada, mas que, apesar disso, gera vítimas.

A intuição da autora parte da observação da realidade da xenofobia, ou rechaço ao estrangeiro. Ela não acontece diante dos turistas ou dos estrangeiros que possuem posses, ao contrário, com relação a eles o que se vê é uma xenofilia, ou amizade e aproximação. A reação se altera notavelmente, no entanto, quando se trata de imigrantes e refugiados pobres. É aí que se percebe a xenofobia. Assim sendo, a causa do rechaço não seria o fato de serem estrangeiros, mas o fato de que sejam pobres, de não trazerem recursos, mas, ao menos aparentemente, trazerem problemas. A aporofobia traria em si uma atitude excludente de quem nada tem a retribuir num "mundo construído sobre o contrato político, econômico e social" (CORTINA, 2017, p. 14), em que as pessoas ou grupos sempre têm algo a dar em troca.

Esta fobia, como todas as fobias - como a xenofobia, o racismo, a misoginia, a homofobia e outras formas -, precisa ser combatida para que seja possível falar de dignidade humana, explicita A. Cortina (2017, p. 14-18). Torna-se improdutivo falar de dignidade de maneira abstrata, sem rostos concretos e visíveis, pois apenas diante de pessoas ou grupos concretos o respeito ao outro se concretiza. 
Mas, como trabalhar este respeito para com os pobres diante dos discursos de ódio que caracterizam as fobias?

\subsection{O aparecimento dos discursos de ódio em tempos de crise}

Em tempos de crise, quando quem tem o poder não tem nada de positivo para oferecer à sociedade em termos de ganhos concretos - emprego, renda, educação de qualidade, saúde universalizada - são necessários bodes expiatórios para acusar. É nestes momentos que o discurso e os delitos de ódio prosperam com sucesso.

Os discursos e delitos de ódio se diferenciam de outros tipos de violações em vários pontos. Cortina (2017, p. 33-39) caracteriza os discursos e delitos de ódio em cinco pontos principais.

O primeiro é o fato de que a vítima não é selecionada por sua identidade pessoal, mas por pertencer a um coletivo. Assim, não se ataca ou se nega direitos a uma pessoa conhecida que tenha realizado algo contra alguém, mas são atacados, de maneira generalizada, os pobres, os moradores de rua, os sem-terra, as mulheres, os negros, os homossexuais, os imigrantes.

A segunda característica é que se utiliza uma tática de estigmatização do coletivo, ao atribuir-lhes atos prejudiciais à sociedade. Mesmo que não se possa comprovar, há sempre uma história remota de alguém, na qual os rumores e as notícias falsas contam mais do que os fatos. Assim, o coletivo é desqualificado e socialmente condenado.

Ao ser estigmatizado, justifica-se a incitação ao desprezo. Esta é a terceira caracterização do discurso e delito de ódio. Diz-se que aquele coletivo vai tirar o trabalho das pessoas locais, ou que ele constitui um perigo e uma ameaça para a população ou para o desenvolvimento. Então, os membros daqueles grupos se 
transformam em alvo do delito de ódio, não por serem incompetentes ou por terem feito algo, mas pelo simples fato de pertencerem ao coletivo. E isto acontece nos lugares mais comuns, como as universidades, as empresas, a política ou a rua.

Outra característica do delito é que, quem incita ao ódio está convencido de uma desigualdade estrutural e crê que sua posição é superior à do agredido, e a do agredido é inferior. Assim, a vítima é obrigada a ver-se como inferior e subordinada. Há uma verdadeira convicção de hierarquia. Eliminam-se possíveis competidores, não demonstrando sua falta de competência, mas desacreditandoos, desqualificando-os, de preferência por rumores.

Nestas circunstâncias, não há relação de igualdade e não existe reconhecimento da dignidade do agredido, por isso não é possível exigir ou compartilhar um mínimo de justiça. Ao contrário da formulação kantiana do imperativo categórico do fim em si mesmo, "princípio supremo da ética moderna", no dizer de Cortina (2017, p. 38), o agressor trata a vítima como meio porque não lhe reconhece igual dignidade e a trata como objeto, não um sujeito a ser tomado em conta.

Por fim, há pouca ou nenhuma argumentação. O delito e o discurso de ódio não pretendem dar argumentos, mas expressar desprezo e incitar os outros a compartilhar deste desprezo.

Como fica claro, os discursos do ódio funcionam como ideologia e dificultam o desenvolvimento de estruturas de igualdade. Na verdade, não são discursos, mas monólogos que negam o ouvinte e tratam o interlocutor como objeto, não sujeitos da palavra. Como consequência há ruptura do vínculo de intersubjetividade e destruição da possibilidade de convivência justa. Trata-se de um grande desafio para as instituições do Estado e da sociedade civil. 


\subsection{As peculiaridades da aporofobia em relação aos demais ódios}

A aporofobia, no entanto, possui características peculiares com relação a outros tipos de ódio ou de aversão porque, ao contrário dos outros ódios, ela se volta contra algo que "não pertence à identidade de uma pessoa e nem é uma questão de opção". (CORTINA, 2017, p. 42).

Faz parte da longa história da reflexão ocidental passar da mentalidade de que os pobres são culpados e culpáveis por sua situação à compreensão de que existem causas naturais e sociais da pobreza que uma sociedade justa deve erradicar. Portanto, eliminar a aporofobia passa por eliminar suas bases, ou seja, a pobreza e as relações assimétricas, a partir da criação de instituições econômicas e políticas empenhadas na construção da igualdade.

Com relação às relações assimétricas, a aporofobia pode se dar em relação aos pobres, mas também em relação aos que se encontram em uma pior situação social relativa. Assim, seguindo o pensamento de Cortina, podemos observar como uma família pobre na França despreza os migrantes mais pobres do que eles. Uma família pobre em Roraima, no Brasil, despreza migrantes venezuelanos ou indígenas.

\subsection{A pobreza como carência de meios e de liberdade}

Mas, como definir a pobreza? Cortina (2017, p. 129) observa que, em geral, para caracterizá-la se utilizam índices baseados nos níveis de renda, e outros mais complexos que consideram também outras realidades, como o analfabetismo, a esperança de vida, a mortalidade infantil, a moradia, a alimentação ou o ambiente (CORTINA, 2017, p. 129). A partir daí, é possível estabelecer distintos graus de pobreza: a extrema ou absoluta, quando as famílias não podem satisfazer as necessidades básicas para a sobrevivência e são incapazes de sair da pobreza sem ajuda exterior; a moderada, quando as necessidades básicas estão cobertas, mas de modo precário; e a relativa, quando o nível de ingressos econômicos familiares situa a família abaixo da proporção da renda nacional média. 
Porém, a autora apresenta uma definição bastante importante se temos em mente o ser humano em sua dimensão cultural. Esta definição é tomada do economista indiano e Prêmio Nobel, Amartya Sen, em seu livro A ideia de justiça (2009). A pobreza seria a "falta de liberdade e impossibilidade de levar a cabo os planos de vida que uma pessoa, segundo suas razões, valorize" (CORTINA, 2017, p. 43). A ideia apoia-se no fato de que, se as pessoas são iguais diante da lei, suas necessidades, desejos e esperanças não são. Portanto, superar a pobreza é poder levar adiante os planos de vida que as pessoas têm como valor, desenvolver a capacidade de ser sujeito de seu próprio caminho de felicidade, em sua proposição e em sua realização.

\subsection{Os condicionamentos impostos pelo "cérebro aporófobo"}

Uma das novidades do pensamento de A. Cortina é o estudo de aspectos da neuro-identidade humana, segundo a qual o ser humano é, ao mesmo tempo, social e individualista. A tendência a ver um nós contra eles, no estudo de Adela, mostrase anterior ao sedentarismo e à cultura grega sobre a ética; ela está incorporada ao nosso cérebro antes do auge da civilização. Trata-se de um código cultural que nasce com o homo sapiens.

No desenvolvimento do cérebro, ao longo de milhões de anos, várias tendências entram em conflito. $\mathrm{O}$ autointeresse desenvolve uma autoconsciência básica e encaminha o humano à sobrevivência, o que implica estar bem alimentado, sentir-se seguro, reproduzir-se etc. Por sua vez, a orientação de controle busca o que é familiar, a segurança, o conhecido, o que faz com que o estranho produza insegurança e incômodo. Por fim a dissociação é a tendência a distanciar-se do que é desagradável. A aporofobia teria aqui, na opinião da autora (CORTINA, 2017, p. 73), uma raiz biológico-neuronal: a tendência a afastar-se do que parece perturbador e o desenvolvimento de emoções sociais defensivas. 
Por outro lado, Cortina (2017, p. 74-75) mostra que se desenvolvem tendências agregadoras e de conduta cooperativa, através da simpatia seletiva, ou capacidade de cuidar do outro, da descendência indefesa, parentes e amigos, pessoas próximas ou a comunidade. Porém, o vínculo do cuidado é seletivo. As pesquisas modernas, com técnicas de neuroimagens, mostram claramente como a situação das pessoas próximas afetam emocionalmente os envolvidos, mas o mesmo não acontece com relação aos estranhos. Desenvolve-se também a empatia, enquanto capacidade de compreender os sentimentos de outros, colocar-se em seu lugar - mas esta capacidade não implica, necessariamente, um compromisso para com o outro.

Caracteriza também a conduta humana a capacidade de reciprocar, ou seja, de ações que "não se explicam pelo parentesco, mas pela expectativa de reciprocidade” (CORTINA, 2017, p. 78). Paulatinamente, ao longo da evolução, praticou-se a cooperação e o intercâmbio para a sobrevivência. De fato, a cooperação se mostrou mais eficaz do que o fechamento nos grupos. Porém, a cooperação se deu com os grupos de que podiam obter algo em troca, formando o "nós" do benefício mútuo.

Ora, este intercâmbio exclui os áporoi - os que não trazem vantagem no jogo das trocas e intercâmbios. O pobre está fora do jogo de dar e receber. São "sem poder”, descritos por Cortina (2017, p. 80-81) como o enfermo mental, os sem função, os sem amigos bem situados, os que não podem devolver favores, postos de trabalho, dinheiro, votos, apoio para ganhar eleições, honras ou presentes que satisfazem a vaidade.

O dado assustador é que, embora o contexto atual tenha mudado substancialmente em comparação com as sociedades originárias, a espécie humana permaneceu essencialmente igual no nível biológico e genético nos últimos 40.000 anos, com as tendências dos grupos de benefício mutuo de um cérebro contratualista, demonstrando que o progresso moral não se herda geneticamente. Ele é construído em cada pessoa, em conexão com aquelas pessoas que a ajudam a viver sua vida. 
A boa notícia, como afirma Cortina, é que "afortunadamente, o cérebro é sumamente plástico e permite cultivar a abertura ao outro, a qualquer outro, a partir do reconhecimento compassivo, que é a chave de uma hospitalidade universal." (CORTINA, 2017, p. 167). O cérebro deixa-se influenciar socialmente, inclusive antes do nascimento, de tal forma que se pode dizer que a construção do cérebro é biossocial. A aprendizagem e a experiência estão mescladas com a ação dos gens em cada pessoa humana.

Pela própria plasticidade do cérebro, é possível ir além dele, em direção ao mundo dos valores, do reconhecimento e da compaixão.

\subsection{Perspectivas de superação da aporofobia}

Ao longo de sua reflexão, A. Cortina descreve algumas perspectivas de superação da aporofobia. Elas se situam no nível da educação e da construção de instituições capazes de criar uma democracia inclusiva. A negação desta inclusão seria uma regressão e um reforço, no nível cultural e institucional, das tendências egoístas, comunitaristas e contratualistas presentes no nível bioneural. Ou seja, em continuidade com o raciocínio do tópico anterior, é possível dizer que a exclusão do outro diferente, no nível social e institucional, significaria um reforço das tendências mais primitivas no nível do desenvolvimento cerebral humano, tal como se deu nos últimos 40.000 anos.

$\mathrm{Na}$ perspectiva do discurso e da linguagem, a superação da aporofobia implica ir em direção a um mundo de liberdade, construída a partir do respeito ativo. Numa sociedade pluralista e democrática, importa empoderar moralmente os sujeitos, defender as bases sociais da autoestima e tratar os pobres como interlocutores válidos, não como seres que merecem o ódio, o desprezo, o rechaço por sua situação social, cor de pele, etc. (CORTINA, 2017, p. 58-59; CORTINA, 1997, p. 215). O pior castigo é ignorar a existência do outro, a rejeição, o desprezo. A base de uma sociedade inclusiva é o reconhecimento recíproco, que constitui o humano como humano e faz possível a ele levar adiante a sua vida. 
É preciso caminhar para o reconhecimento recíproco da dignidade e para a compaixão que rompe barreiras, que não estão escritas no cérebro, mas nas tradições culturais que fazem do reconhecimento e da compaixão a experiência humanizadora por excelência. Descobrir o vínculo de pertencimento mútuo faz surgir obrigações de justiça, que nascem do respeito pela dignidade do outro.

Mas este reconhecimento não é apenas da dignidade do outro, é também reconhecimento de que todas as vidas estão originariamente vinculadas, por isso a vida deve ser vivida a partir da compaixão. O reconhecimento do vínculo originário gera também as obrigações que nascem do mundo novo e aconchegante da gratuidade (CORTINA, 2017, p. 100-101).

Cortina propõe que a educação do século XXI deveria formar pessoas de seu tempo; de seu lugar concreto e abertas ao mundo; sensíveis ao sofrimento, ao drama da pobreza extrema, da fome, das mortes prematuras, das doenças sem atenção; reconhecer o dever dos países a oferecer hospitalidade; “cidadãos compassivos, capazes de assumir a perspectiva dos que sofrem mas, sobretudo, de comprometer-se com eles" (CORTINA, 2017, p. 168).

Interessante a síntese da autora. Em sua proposta de superação da aporofobia, articula duas categorias diferentes, cidadania e compaixão. Une o ser político, consciente de direitos e deveres de justiça, e a compaixão que logra sensibilizar-se diante do vínculo originário entre todos, em perspectiva de superação do egoísmo e saída de si em direção ao outro que mais necessita.

\section{A opção pelos pobres diante da aporofobia: pistas antropológico-teológicas para avançar}

O estudo de Adela Cortina traz luzes novas para a complexidade da opção pelos pobres. Por um lado, contribui com uma visão menos ingênua da liberdade humana, pois a aporofobia encontra-se enraizada no próprio modo de 
sobrevivência e evolução do homo sapiens. Por outro, abre para as potencialidades educativas e institucionais, não menos robustas. No diálogo de Cortina com a teologia, e principalmente com a antropologia, podemos entrever algumas pistas para avançar.

\subsection{Redescobrir a opção pelos pobres como graça}

O estudo de Cortina nos mostra que há uma distância entre a moral pensada, escrita e declarada - sempre pautada por valores universalistas - e a moral realmente vivida - normalmente pautada pelo egoísmo ou pelo favorecimento de amigos e familiares próximos, pois prevalecem o autointeresse, a orientação de controle, a dissociação e a simpatia seletiva. A esta distância se chamou, filosoficamente, de fraqueza moral (akrasia) (CORTINA, 2017, p. 66).

A teologia cristã permite outra reflexão. A esta distância entre o desejo declarado e a ação realizada, descrita na Carta de Paulo aos Romanos $7(\mathrm{Rm} 7,19)$, a tradição cristã denominou pecado original e este, antes de remeter ao fracasso humano, remete à força da graça libertadora de Deus e da fé. A ênfase está na ação de Deus mesmo.

Assim, a opção pelos pobres é dom e bem-aventurança a ser acolhida. "E serás feliz!" (Lc 14,14), exclama Jesus no evangelho de Lucas, dirigindo-se àquele que deu uma festa e preparou uma refeição para aqueles que nada podiam retribuir: os pobres, os aleijados, os coxos, os cegos. A gratuidade do Reino de Deus é uma bem-aventurança a ser descoberta, acolhida e vivida em humildade.

Vigil (2000, p. 298) nos diz que a opção pelos pobres é teologal, ou seja, fundamenta-se no próprio Deus que não faz mas que "é opção pelos pobres". Ela pertence à mensagem central do Reino de Deus, uma dimensão essencial e constitutiva do projeto de Deus em Jesus. Por mais que se queira e deva universalizar o amor cristão, "não se pode negar, na práxis messiânica de Jesus, a 
centralidade e prioridade dada aos caídos à beira do caminho: pobres, enfermos, pecadores públicos, 'possessos', marginalizados”, nos lembra Aquino. (AQUINO, 2016, p. 251).

A solidariedade concreta e o seguimento de Jesus estão ancorados na misericórdia de Deus que se revela em Jesus Cristo. É Ele, com seu amor que, no Espírito cria em nós o amor, a compaixão capaz de arrancar-nos de nossos próprios interesses. Colocar-se no seguimento de Jesus é, nas palavras de Andrade, “colocarse no seguimento do Amor misericordioso de Deus, deixar-se invadir por este amor que faz com que busquemos o necessitado para nos colocarmos ao seu lado como irmãos.” (ANDRADE, 2011, p. 173). E, remetendo à denotação de misericórdia como entranhas vulneráveis, segue: "é abrir as entranhas, aceitar o convite para a festa onde se entra para partilhar a mesma alegria do pai solidário (Lc 15,31-32)”.

Finalmente, o Papa Francisco lembra que Deus manifesta a sua misericórdia, antes de tudo, aos pobres e que "esta preferência divina tem consequências na vida de fé de todos os cristãos, chamados a possuírem 'os mesmos sentimentos que estão em Cristo Jesus' (Fl 2, 5)" (FRANCISCO, 2013, p. 120, n. 198).

\subsection{A necessidade do envolvimento emocional com os pobres}

O estudo de Adela Cortina nos mostrou, através das pesquisas com neuro imagens, como somos afetados emocionalmente com o que acontece com pessoas próximas e queridas, o que não acontece com as pessoas que não conhecemos ou rejeitamos - neste caso é o lado racional a ser afetado.

Vemos como a opção pelos pobres, para ser efetiva, exige um envolvimento afetivo, um fazer-se próximo e amigo dos pobres. 
O Documento de Aparecida, como já foi visto, avançou nesta direção, ao sugerir prestar aos pobres "amável atenção", "escutá-los com interesse”, "escolhelos para compartilhar horas, semanas ou anos de nossa vida" (APARECIDA, 2007, p. 179, n. 397).

O Papa Francisco (2013), em seus recentes documentos, também avança. O contato físico refaz vínculos e faz ver de forma diferente aos pobres. O serviço e a promoção dos pobres implica "atenção", "solicitude", "novas convicções que entranhem as estruturas", faz-se necessário "alongar mais o olhar e abrir mais os ouvidos" (FRANCISCO, 2013, p. 113-115, n. 187-190). É preciso "uma proximidade real e cordial" (FRANCISCO, 2013, p. 121, n. 199).

Na Encíclica Laudato Si, Francisco lamenta que, nos planejamentos das cidades, os pobres fiquem em último lugar na hora da implementação de decisões. Os profissionais e poderes públicos não tomam contato direto com eles, não os conhecem fisicamente e, consequentemente, são incapazes de tomar decisões que façam justiça aos injustiçados ou os favoreçam (FRANCISCO, 2015, p. 34, n. 49). Há um verdadeiro desconhecimento dos problemas que afetam os excluídos, devido à ausência de um contato mínimo com eles por parte de quem toma as decisões.

\subsection{Descobrir a riqueza dos pobres e recusar o discurso do ódio}

A aporofobia é alimentada pela tendência contratualista das relações, segundo a qual os grupos se aproximam por interesses. Os pobres seriam, nesta visão preconceituosa, os que não têm nada para dar. Evidentemente não é esta a visão do Evangelho, os pobres nos revelam o rosto e os sentimentos de Cristo, nos inserem nas bem-aventuranças do Reino. 
Porém, é preciso avançar espiritualmente em descobrir a riqueza dos pobres, e o envolvimento é o caminho. A Laudato $S i$ ' nos traz um exemplo desta descoberta, que não deixa de chamar a atenção do leitor. Trata-se da cálida descrição do interior das casas nas favelas insalubres. No texto abaixo, pode-se observar o envolvimento e a valorização dos pobres:

Nalguns lugares onde as fachadas dos edifícios estão muito deterioradas, há pessoas que cuidam com muita dignidade o interior das suas habitações, ou que se sentem bem pela cordialidade e amizade das pessoas. A vida social positiva e benfazeja dos habitantes enche de luz um ambiente à primeira vista inabitável. É louvável a ecologia humana que os pobres conseguem desenvolver, no meio de tantas limitações. A sensação de sufocamento, produzida pelos aglomerados residenciais e pelos espaços com alta densidade populacional, é contrastada se se desenvolvem calorosas relações humanas de vizinhança, se se criam comunidades, se as limitações ambientais são compensadas na interioridade de cada pessoa que se sente inserida numa rede de comunhão e pertença. Deste modo, qualquer lugar deixa de ser um inferno e torna-se o contexto duma vida digna. (FRANCISCO, 2015, p. 92-93, n. 148).

É preciso "apreciar o pobre na sua bondade própria, com o seu modo de ser, com a sua cultura, com a sua forma de viver a fé" (FRANCISCO, 2013, p. 120-121, n. 199).

O envolvimento emocional e a descoberta da riqueza dos pobres são a melhor forma de recusar o discurso do ódio, característico da aporofobia. Tal discurso é alimentado pelo preconceito, desqualificação, invisibilização e eliminação sistemática. Ao contrário, o contato é verdadeiro discurso, pois considera o outro sujeito e busca a sua promoção e empoderamento para melhor dialogar e fazer valer sua palavra no jogo social.

Neste aspecto, a proposta de A. Cortina sobre o "vínculo originário" que pode ser rompido ou fortalecido é bastante iluminador. Teologicamente, este vínculo nos vem da unidade de origem e destino de toda a humanidade. E, nesta vida, vamos nos conscientizando e agindo em consequência com a realidade da interligação de todos os humanos, e todos os seres. "Tudo está interligado", se não se reconhece o pobre, o doente, o frágil, fica difícil reconhecer os gritos da natureza (FRANCISCO, 2015, p. 74, n. 117). 


\subsection{Eliminar a pobreza, cuidar de instituições e educação com valores universalistas e não elitistas}

A aporofobia é melhor combatida com a eliminação da pobreza. Como foi visto, a pobreza deve ser vista não apenas de forma econômica, mas também como falta de liberdade para viver segundo os próprios valores.

No Magistério de Francisco, "cada cristão e cada comunidade são chamados a ser instrumentos de Deus a serviço da libertação e promoção dos pobres, para que possam integrar-se plenamente na sociedade", "somos os instrumentos de Deus para ouvir os pobres" (FRANCISCO, 2013, p. 114, n. 187) e "ninguém pode sentir-se exonerado da preocupação pelos pobres e pela justiça social”. (FRANCISCO, 2013, p. 122, n. 201).

Ouvir a exigência deste clamor é obra de Deus e deriva da graça libertadora em cada um de nós - por isso é preciso formar novas convicções e atitudes que entranhem as estruturas. Trata-se de um círculo vicioso que implica atitude interior e ação. (FRANCISCO, 2013, p. 114-115, n. 188-189).

O que se deseja é mais do que o sustento, mas a educação, cuidados de saúde e, especialmente trabalho livre, criativo, participativo e solidário. Com salário justo que permita o acesso adequado aos outros bens que estão destinados ao uso comum. (FRANCISCO, 2013, p. 116, n. 192).

O princípio do bem comum, basilar na Doutrina Social da Igreja, deve ser pensado sem abstrações, a partir de rostos concretos. Em sociedades como as nossas, em que as desigualdades são numerosos e mais pessoas são descartados e privadas dos direitos fundamentais, pensar o bem comum

torna-se imediatamente, como consequência lógica e inevitável, um apelo à solidariedade e uma opção preferencial pelos mais pobres. Esta opção implica tirar as consequências do destino comum dos bens da terra, mas exige acima de tudo contemplar a imensa dignidade do pobre à luz das mais profundas convicções de fé. (FRANCISCO, 2015, p. 97, n. 158). 


\subsection{Uma nova economia}

A fé no Deus da vida fez a teologia recuperar a economia como um âmbito da fé, que exige renúncia à idolatria do mercado e outra forma de se pensar o bem comum e a distribuição de bens (MO SUNG, 1994, p. 269). Este trabalho é ainda incipiente.

A Exortação Evangelii Gaudium, de Francisco, na esteira de documentos anteriores do magistério, convida a tomar a sério a proposta de uma nova economia. Dentre as orientações presentes nessa Exortação, três podem ser ressaltadas.

A primeira, renunciar à autonomia absoluta dos mercados, à confiança nas forças cegas e na mão invisível do mercado, à especulação financeira e atacar as causas estruturais da desigualdade social. (FRANCISCO, 2013, p. 123, n. 202).

A segunda, abrir o discurso da política econômica aos temas que importam à humanidade. Nesta reestruturação da política econômica, falar do bem comum e da dignidade humana, de ética, de solidariedade mundial, de distribuição de bens, de defesa de postos de trabalho, de dignidade dos fracos, de um Deus que exige compromisso com os pobres não seria um incômodo, como é diante do atual sistema econômico. (FRANCISCO, 2013, p. 123, n. 202).

Por último, um convite àqueles "que vivem uma mentalidade individualista, indiferente e egoísta": que possam "libertar-se dessas cadeias indignas e alcancem um estilo de vida e de pensamento mais humano, mais nobre, mais fecundo, que dignifique a sua passagem por esta terra” (FRANCISCO, 2013, p. 125, n. 208). 


\section{Conclusão}

A opção preferencial pelos pobres, solenemente proclamada em Puebla, é decorrente de um dinamismo de amor e graça, que move os cristãos a realizarem a justiça no mundo, tendo como fundamento a verdade do Evangelho, como sinal a liberdade e como fim a comunhão de toda a humanidade. Sua influência na teologia, nos documentos episcopais latino-americanos e universais é notável. Seu caráter profético provoca deslocamentos de posturas pessoais, eclesiais, com alcance para o mundo da economia política e da cultura.

No entanto, ela se encontra fortemente desafiada pela rejeição aos pobres, que o recente estudo de Adela Cortina definiu como aporofobia. A aporofobia se alimenta e alimenta discursos de ódio que desqualificam e eliminam os pobres, especialmente em tempos de crise. O combate à aporofobia passa pela eliminação da pobreza e por uma concepção econômica que associe o combate à pobreza não apenas à aquisição de bens, mas também ao crescimento da liberdade para desenvolver os caminhos próprios de felicidade. Um fator complicador da aporofobia são as novas descobertas no campo bioneural, que afirmam a natureza defensiva e a simpatia seletiva do cérebro. Por outro lado, o cérebro se mostra plástico às aquisições éticas e compassivas através da educação e das instituições. Por isso, impõe-se o reconhecimento da dignidade dos pobres e de seus direitos de cidadania, além do desenvolvimento da compaixão capaz de assumir a perspectiva dos que sofrem.

Diante disso, a teologia, em especial a antropologia teológica, é chamada a redescobrir a opção pelos pobres como graça, a perceber a necessidade do envolvimento emocional com os pobres, a descobrir a riqueza e protagonismo dos pobres e recusar o discurso do ódio, a refletir sobre caminhos para eliminar a pobreza e aumentar a liberdade para uma vida segundo os valores da pessoa ou grupo, cuidar de instituições e educação com valores universalistas e não elitistas e a contribuir para uma nova economia. Em tudo isto, o magistério de Francisco mostra-se profundamente iluminador. 


\section{REFERÊNCIAS}

ANDRADE, Paulo Fernando Carneiro de. A opção pelos pobres e a misericórdia de Deus. In: OLIVEIRA, Pedro Ribeiro de. Opção pelos pobres no século XXI. São Paulo: Paulinas, 2011. cap. 3, p. 157-173.

AQUINO JÚNIOR, Francisco. Questões fundamentais de Teologia da Libertação. Perspectiva Teológica, Belo Horizonte, v. 48, n. 2, p. 245-268, maio/ago. 2016.

BÍBLIA. Tradução Ecumênica da Bíblia (TEB). São Paulo: Paulinas: Loyola, 1995.

CORTINA, Adela. Aporofobia, el rechazo al pobre: un desafio para la democracia. Barcelona: Paidós, 2017.

CORTINA, Adela. Ciudadanos del mundo: hacia una teoria de la cidadania. Madrid: Alianza Editorial, 1997.

CTA. Espiritualidade de encarnação da Instituição Teresiana: uma reflexão a partir da teologia latino-americana. Rio de Janeiro: Novamerica, 2007.

FRANCISCO, Papa. Carta Encíclica Laudato Si’: sobre o cuidado da casa comum. Brasília: CNBB, 2015.

FRANCISCO. Exortação Apostólica Evangelii Gaudium: a alegria do Evangelho. Brasília: CNBB, 2013.

GUTIERREZ, Gustavo. Una teología de la Liberación e el contexto del tercer milenio. In: CELAM. El futuro de la reflexión teológica en América Latina. Bogotá: CELAM, 1996.

II CONFERÊNCIA GERAL DO EPISCOPADO LATINO-AMERICANO. MEDELLÍN, 1968. In: CONSELHO EPISCOPAL LATINO-AMERICANO. Documentos do CELAM: Rio de Janeiro, Medellín, Puebla, Santo Domingo. São Paulo: Paulus, 2005 p . 71-224.

III CONFERENNCIA GERAL DO EPISCOPADO LATINO-AMERICANO. PUEBLA, 1979. Evangelização no presente e no futuro da América Latina. In: CONSELHO EPISCOPAL LATINO-AMERICANO. Documentos do CELAM: Rio de Janeiro, Medellín, Puebla, Santo Domingo. São Paulo: Paulus, 2005. p. 225-584.

IV CONFERÊNCIA GERAL DO EPISCOPADO LATINO-AMERICANO. SANTO DOMINGO, 1992. Nova evangelização, promoção humana e cultura cristã. "Jesus Cristo ontem, hoje e sempre" (Hb 13,8). In: CONSELHO EPISCOPAL LATINO-AMERICANO. Documentos do CELAM: Rio de Janeiro, Medellín, Puebla, Santo Domingo. São Paulo: Paulus, 2005. p. 585-782.

JOÃO PAULO II. Carta apostólica Tertio Millennio Adveniente: sobre a preparação para o jubileu do ano 2000. Disponível em: http://w2.vatican.va/content/john-paulii/pt/apost_letters/1994/documents/hf_jp-ii_apl_19941110_tertio-millennioadveniente.html. Acesso em: 28 jul. 2019. 
JOÃO PAULO II. Encíclica Centesimus Annus: no centenário da Rerum Novarum. Disponível em: http://w2.vatican.va/content/john-paul-

ii/pt/encyclicals/documents/hf_jp-ii_enc_01051991_centesimus-annus.html. Acesso em: 28 jul. 2019.

JOÃO PAULO II. Encíclica Redemptoris Missio: sobre a validade permanente do mandato missionário. 1990. Disponível em: http://w2.vatican.va/content/john-paulii/pt/encyclicals/documents/hf_jp-ii_enc_07121990_redemptoris-missio.html. Acesso em: 28 jul. 2019.

JOÃO PAULO II. Encíclica Sollicitudo Rei Socialis: sobre a solicitude social da Igreja. 1987. Disponível em: http://w2.vatican.va/content/john-paul-

ii/pt/encyclicals/documents/hf_jp-ii_enc_30121987_sollicitudo-rei-socialis.html. Acesso em: 28 jul. 2019.

MO SUNG, Jung. Teologia e economia: repensando a teologia da libertação e utopias. Petrópolis: Vozes, 1994.

SEN, Amartya. A ideia de justiça. Tradução de Ricardo Doninelli Mendes e Denise Bottmann. São Paulo: Editora Schwarcz Ltda, 2009.

V CONFERÊNCIA GERAL DO EPISCOPADO LATINO-AMERICANO E DO CARIBE. DOCUMENTO DE APARECIDA. Texto Conclusivo. Brasília: CNBB; São Paulo: Paulus: Paulinas, 2007.

VIGIL, José María. Opção pelos pobres e trabalho da teología. In: SUSIN, L. C. (org.). Sarça ardente. Teologia na América Latina: prospectivas. Belo Horizonte: SOTER; São Paulo: Paulinas, 2000. p. 297-307. 